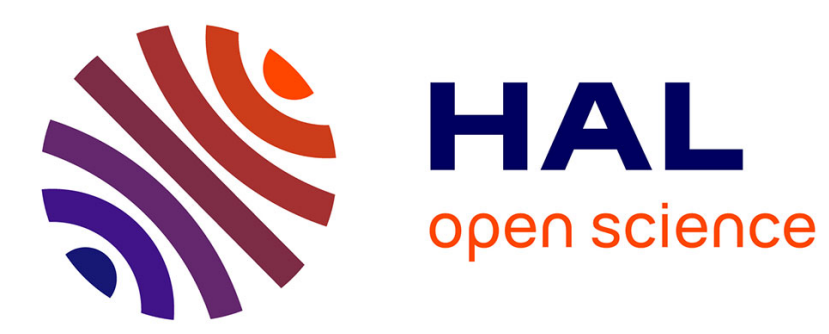

\title{
El encuentro del tabardillo. Introducción a algunos procesos narrativos en purépecha
}

Claudine Chamoreau

\section{To cite this version:}

Claudine Chamoreau. El encuentro del tabardillo. Introducción a algunos procesos narrativos en purépecha. Tlalocan, 2004, 14, pp.95-131. halshs-00293461

\section{HAL Id: halshs-00293461 https://shs.hal.science/halshs-00293461}

Submitted on 4 Jul 2008

HAL is a multi-disciplinary open access archive for the deposit and dissemination of scientific research documents, whether they are published or not. The documents may come from teaching and research institutions in France or abroad, or from public or private research centers.
L'archive ouverte pluridisciplinaire HAL, est destinée au dépôt et à la diffusion de documents scientifiques de niveau recherche, publiés ou non, émanant des établissements d'enseignement et de recherche français ou étrangers, des laboratoires publics ou privés. 
El relato que analizo en este trabajo me fue contado en septiembre de 1996 por don Agustín Téllez (q.e.p.d.). Aunque residía en la capital mexicana, Tata Agustini estaba muy arraigado a la vida de su pueblo y en particular a sus fiestas. Tenía un amplio conocimiento de la lengua, de la cultura y de la música purépechas, al igual que su esposa doña Audelia Ponce, quien siempre lo acompañaba. Quisiera aquí rendir un homenaje a su memoria, su pasión, su paciencia y su gentileza.

En este trabajo, después de describir someramente los festejos del mes de diciembre en Tiríndaro, pueblo del cual don Agustini era originario (\$1), se analizan dos procesos narrativos de la lengua purépecha: los marcadores transfrásticos y el infinitivo narrativo (\$2). Finalmente, se presenta el relato en purépecha, seguido de su traducción al español y de su análisis monemático (\$3).

\section{El relato: una manifestación de la tradición oral}

El relato de Tata Agustini ofrece una descripción de los festejos de diciembre en Tiríndaro, pueblo ubicado al noreste del Lago de Pátzcuaro, perteneciente al municipio de Zacapu y a la región de La Ciénega. Esta comunidad sigue un calendario de festejos que incluyen los Santos Reyes el 6 de enero, el Fuego Nuevo o la Calendaria el 2 de febrero, la Cuaresma en fecha movible que culmina con la Semana Santa, la Virgen del Rosario el 13 de mayo, la Ceremonia a los Muertos el 1 y 2 de noviembre, el Día del Músico el 22 de noviembre, la festividad a la Virgen de Guadalupe el 12 de diciembre y las Posadas y fiestas navideñas a partir del 15 de diciembre.

En las fiestas de diciembre, los jóvenes, designados en este relato como los pastores, van al cerro a cortar una planta silvestre, el takari 'tabardillo' (Piquieiria trinervia). Además de Michoacán, es posible encontrar esta planta en otros estados de la República tales como San Luis Potosí, Hidalgo, Nayarit, Puebla. Se describe como una 'planta herbácea de un metro de altura, con hojas opuestas, ovaladolanceoladas, dentadas y con tres nervaduras bien visibles' (Martínez, 1979: 829). 
El relato está centrado en el tabardillo como símbolo de encuentro y de unión: búsqueda y encuentro de las plantas, encuentro de los jóvenes, unión de la tradición con la modernidad, huella de la importancia de la naturaleza dentro de la cultura vista como dinámica. La naturaleza a través del takari permite también la unión de las generaciones, así como la conservación de la tradición.

A finales de diciembre los jóvenes salen del pueblo, van a cortar el takari al cerro cercano. Cuando regresan, el carguero acompañado por diversos miembros de la comunidad los están esperando con una rica cena, por lo general pozole. Empiezan entonces a actuar los músicos, los danzantes y los cantores. La fiesta se extiende en todo el pueblo. Después se adornan la casa del carguero y el templo con el takari, esparciéndolo en el suelo. El tiempo y el espacio presentan varias dimensiones. La fiesta se desarrolla durante varios días con eventos por la mañana, por la tarde y durante la noche. Las personas que participan se desplazan dentro del pueblo y también fuera de éste, en el cerro, lugar donde se encuentra el takari. Estos acontecimientos explican el título del relato 'Encuentro del tabardillo' o con mayor precisión 'El encuentro con los jóvenes que traen el tabardillo'.

En estas fiestas destacan varios personajes muy importantes: en particular los pastores, los viejos y las maringuias. Los pastores, generalmente jóvenes, van a recolectar el takari para adornar la casa del carguero, el templo y el lecho del Niño Dios. Después trasladan al Niño Dios de la iglesia a la casa de alguno de ellos, en particular el carguero principal. Durante los días de posadas se rezan rosarios, se distribuye dinero y se canta para el Niño Dios. Los músicos andan junto con los danzantes, a quienes los habitantes de Tiríndaro llaman thare 'viejo'. Los danzantes van vestidos con una camisa y un calzón de manta bordados, una faja negra, y portan una máscara de madera y un sombrero de cuya copa terminada en punta se desprende un par de listones. Estos hombres no bailan solos, sino que lo hacen acompañados de un personaje llamado la maringuia. La maringuia es un hombre vestido de mujer, con una falda larga, un delantal, una camisa, una faja gruesa y un sombrero. Se cubre la cara con un pañuelo, dejando ver solamente los ojos. Agita un pañuelo bordado que sirve para hacer bailar o, en palabras del narrador, para torear al viejo. Acompañados de los músicos, los danzantes bailan en el pueblo la pieza llamada el Toro. La participación activa de todo el pueblo es muy importante en esta celebración. Para recompensar a los danzantes, los miembros de la comunidad les ofrecen frutas, maíz, pinole, esquite o inclusive dinero: el 'aguinaldo'.

Este festejo mantiene viva una tradición religiosa católica traída por los españoles: las posadas. En éstas, el viejo y la maringuia representan la pareja bíblica de 
José y la Virgen María en su peregrinación de Nazaret a Belén, que culmina con el nacimiento de Jesús (representado por el Niño Dios). Esta manifestación tiene sus orígenes en la religión católica, sin embargo existen similitudes notables con la cultura tarasca prehispánica. Aunque limitados dada la escasez de fuentes documentales, los estudios realizados sobre el calendario tarasco (León, Paso y Troncoso y Caso) muestran un número muy importante de fiestas, una cada mes durante todo el año. ${ }^{1}$ La fiesta que se celebraba por estas fechas era llamada Peuanscuaro. Este término significa 'lugar de renacimiento' y se celebraba en el mes que va del 5 al 24 de diciembre. La coincidencia del nombre de esta fiesta y el acontecimiento cristiano es relevante para que los dos festejos puedan mezclarse, creando un sincretismo en el que probablemente sobreviven tradiciones culturales tarascas prehispánicas dentro de una fiesta aparentemente cristiana.

Esta celebración del mes de diciembre conjuga elementos religiosos y participación festiva pagana del pueblo. La presencia musical y la participación social reflejan la manifestación popular del festejo. La música está presente con la banda de músicos y sus diferentes instrumentos: por ejemplo, la tarola, la flauta de carrizo. La pieza musical que se toca en estas ocasiones es el Toro, conocida también como el Torito. La expresión de la música está estrechamente relacionada con las de la danza y del canto. Los músicos, los danzantes y los cantantes son grupos artísticos complementarios entre sí y ligados a las fiestas. Estas tres expresiones participan del festejo en cada momento, son componentes activos y le dan su vitalidad. Otro factor indispensable es la participación de los habitantes, que es una condición de la existencia y persistencia de tales fiestas: se realizan por el pueblo y para el pueblo. La fiesta, como manifestación pagano-religiosa, está muy vigente en toda el área purépecha. En el relato, destaca la participación del pueblo como un conjunto unido. En ciertas oraciones, el narrador utiliza la construcción pasiva, que permite expresar un agente colectivo indefinido, por ejemplo: ariranani 'se interpretan' $(\mathrm{T} 34)^{2}$, waranasinti 'se baila' (T66).

El relato de Tata Agustini no pertenece al repertorio de la tradición oral purépecha, es el relato de un acontecimiento, de una fiesta. Una fiesta es una herencia cultural y social al igual que los cuentos, sin embargo son manifestaciones que presentan diferencias. Una fiesta se presenta como un acto dinámico de un grupo

\footnotetext{
${ }^{1}$ El ciclo anual tenía dieciocho meses.

${ }^{2}$ Los números de los ejemplos que provienen del texto El encuentro del tabardillo aparecen siempre precedidos por una $T$ : (T1), por ejemplo corresponde al primer enunciado del texto. Cuando los enunciados no pertenecen a ese relato, aparecen simplemente numerados (1).
} 
social en el cual algunos miembros son 'actores' con un papel particular y los otros son participantes, pocos son espectadores. Este proceso activo se presenta en una fecha particular, es una manifestación simbólica de un evento religioso, histórico, etc. Su fuerza es por un lado el carácter repetitivo, que mantiene viva la tradición - existen actos que siempre deben de ocurrir - y por otro lado las especificidades efímeras de cada representación en las cuales algunos acontecimientos son novedosos, enriquecen o cambian la fiesta. Por otro lado, un cuento no necesita para expresarse un escenario particular ni un calendario específico. El 'actor' principal es el narrador y puede intervenir en cualquier momento, en cualquier situación y ante cualquier persona, que a su vez es un posible futuro narrador. Se pueden organizar ceremonias específicas para narrar cuentos, sin embargo no se necesita siempre de una 'representación' particular. Cada narración es a la vez una repetición del cuento y una re-creación de éste: constituye no solamente la evocación de un recuerdo sino también una reconstrucción mental.

El relato de una fiesta no es la representación de la fiesta: es una manifestación oral de un acontecimiento, no obstante, presenta muchos rasgos culturales y lingüísticos similares a los de la narración de un cuento. En el nivel etnográfico, ya sea una fiesta, el relato de una fiesta, un cuento o una leyenda, son las expresiones de la transmisión de una herencia cultural, de una memoria étnica. Son hechos tradicionales anclados en una cultura que presentan procesos dinámicos y que pertenecen a todos y a nadie, se pueden definir como un patrimonio cultural común. Asimismo, se conservan las costumbres, narrándolas a las futuras generaciones. Espejo en el cual se mantiene, se construye y se re-construye una cultura, la narración de cuentos y de eventos permite a una sociedad proyectarse tal como es, como quisiera ser o como teme ser. En el nivel lingüístico, el relato se construye con algunos procesos narrativos particulares que se manifiestan también en los cuentos y las leyendas.

\section{Algunos procesos narrativos}

El purépecha es una lengua hablada por alrededor de 100, 000 personas, esencialmente en el estado de Michoacán (México). Se define como una lengua aislada que se puede caracterizar de la manera siguiente: sus formas dialectales presentan una cierta unidad lingüística; a pesar de algunas diferencias, en particular fonológicas, existe una intercomprensión más o menos amplia según las variantes. Su implanta- 
ción geográfica ofrece una cierta unidad: la región purépecha se localiza en el noreste del estado de Michoacán. Las diferentes zonas geográficas que la componen son cercanas entre sí (la Sierra, al oeste, el Lago de Pátzcuaro al este, la Cañada de los Once Pueblos y la Ciénaga de Zacapu al norte). Se puede destacar una homogeneidad étnico-cultural de los hablantes de purépecha, a pesar de que se pueden distinguir también algunos rasgos peculiares en cada comunidad. Finalmente, ninguna relación genética con otras lenguas ha sido comprobada hasta ahora.

El purépecha es una lengua de tradición oral, no obstante existen reflexiones y acciones para desarrollar su transcripción. Cuna de la memoria del pueblo, el relato se puede definir como un libro activo e interactivo. En este sentido, me parece crucial el respeto de las formas lingüísticas propias del relato: indican los procesos que la lengua utiliza para relatar, la manera en la que el narrador insiste en los eventos importantes y las relaciones que existen entre las diferentes partes de la historia narrada. Por estas razones, a continuación la transcripción del relato es fiel a la versión oral tal como fue grabada, con sus dudas y sus repeticiones. Contiene también algunas economías de hechos y eventos que el narrador supone conocidos por el co-narrador.

En este relato aparecen diferentes procedimientos de la narración en purépecha que no ocurren en otras situaciones (diálogos, frases sueltas, etc.). Entre éstos, destacan el infinitivo narrativo, la presencia de $k a$ y ya como marcadores transfrásticos, la importancia de la ubicación anafórica de los participantes, la organización del espacio relacionada con procesos narrativos, la utilización de una modalidad enunciativa (el mediativo), etc. (Chamoreau, en prensa). En esta presentación, me centro solamente en los dos primeros procesos.

\section{A. Los marcadores transfrásticos}

En la mayoría de los relatos se observan dos marcadores transfrásticos: $k a$ introduce los enunciados y ya los concluye. Los relatos son narraciones orales en las cuales no es muy fácil establecer una definición del concepto de enunciado. Por lo tanto, los marcadores $k a$ y ya se presentan en un primer plano como elementos útiles a nivel sintáctico porque proponen una posibilidad de corte, por ejemplo:

$\begin{array}{llllll}\text { (T30) ka tsa únta -ni } & \text { músiku-et } \int a & \text { kústa-ni } & \text { ya } \\ \text { y dem.pl. } & \text { empezar+inf. } & \text { músico }+ \text { pl. } & \text { tocar +inf. } & \text { ya } \\ \text { y ellos, los músicos ya empiezan a tocar } & & & \end{array}$




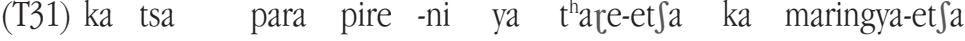 y dem.pl. para cantar+inf. ya viejo + pl. y maringuia + pl. y para que canten ellos, los viejos y las maringuías

Cuando aparece al principio de un enunciado, $k a$ funciona como un marcador transfrástico y se traduce por 'y', 'y después', 'entonces'. No obstante, en ciertos contextos, $k a$ no se comporta como un marcador transfrástico sino como un coordonante, se ubica entonces entre dos unidades, por ejemplo:

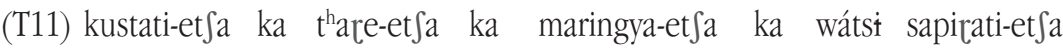
músico + pl. y viejo + pl. y maringuia + pl. y niño pequeño + pl. los músicos, los viejos, las maringuías y los niños pequeños

Por su parte, el marcador ya, elemento probablemente tomado del español, indica que el proceso se efectúa en el momento indicado y puede en ciertos contextos ser interpretado como un perfectivo, expresando una acción terminada. El elemento ya aparece generalmente después del verbo (T31) o al final del enunciado (T30). ${ }^{3}$

En los relatos, los marcadores transfrásticos aparecen con mucha frecuencia: en este relato en particular, $k a$ aparece treinta y siete veces y ya presenta treinta y seis ocurrencias. Además, se pueden encontrar quince contextos en los cuales los dos elementos van juntos, ya-ka (ver por ejemplo líneas atrás en T30-T31). ${ }^{4}$

Aparecen otros marcadores cuya frecuencia es más baja. El término tomado del español, lwégu 'luego' es generalmente postpuesto a ka (T22 y T33).

(T22) ka tsa lwégu músiku-et ja kústa-ni

y dem.pl. luego músico + pl. tocar + inf.

y luego que los músicos toquen

(T33) ka lwéku mátirku

y luego repentinamente

y luego repentinamente

\footnotetext{
${ }^{3}$ Solamente dos excepciones fueron encontradas (Chamoreau, en prensa).

${ }^{4}$ Los marcadores están presentes en los relatos que conservan los rasgos de la narración oral. En relatos de estilo más formales, en los cuales se ha efectuado un trabajo de redacción, se suele eliminar estos marcadores (comparar los textos en Chamoreau, 2003, pp. 177-179 y pp. 193-199).
} 
Los términos ánk $k^{b} u$ y $x a k^{b} a n i$ 'entonces' permiten relacionar lógicamente dos enunciados. El elemento ánk $k^{b} u$ puede presentarse después de $k a$ 'y' (T10, T68) o solo, en este caso podría ser conmutado con $k a$ (T49, T53, T62).

(T53) ánk $k^{\mathrm{h}} u$ ma tarola ánk $\mathrm{h}^{\mathrm{h}} u$ ma karisu ma arí -ra -kata kústani entonces un tarola entonces un carrizo un decir+caus.+part. tocar entonces, tocan la tarola, la flauta de carrizo, una pieza de música

Por su parte, $x a k^{b} a n i$ aparece solo:

(T70) pára xakhani ú -ni t tápata para entonces hacer+inf. tamal para entonces hacer tamales

En otros relatos, se puede encontrar otros marcadores, como tátstik ${ }^{w} a$ 'después' (Chamoreau, en prensa).

Los marcadores transfrásticos proponen instrucciones de cortes de los enunciados. Estos elementos existen gracias a la necesidad de organizar en lo oral la sucesión de los eventos relatados. En segundo lugar, ofrecen la posibilidad de relacionar en el nivel del texto un evento con otro, de enlazar los diferentes enunciados en el nivel temático. Oralmente, la linearidad del relato obliga al narrador a buscar los medios para relacionar lógica y cronológicamente la sucesión de los procesos. Estos marcadores funcionan como indicios de coherencia 'para significar simplemente que el nuevo enunciado continúa el mensaje del enunciado concluido apenas o que desarrolla su tema. Es el $y$ narrativo' (Stati, 1990: 140). Estos elementos refuerzan la adecuación lógica y cronológica entre los enunciados del relato. El enlazamiento de los enunciados del relato corresponde a la sucesión de los eventos en la situación real. Los enunciados se enlazan de manera icónica. Se refleja un paralelismo entre relato lingüístico y hechos extralingüísticos. Sorin Stati (1990: 149) explica que 'la presencia de un marcador no es necesaria cuando la sucesión de los enunciados es paralela a la sucesión de los eventos relatados'. La gran productividad de los marcadores $k a$ y ya en los relatos purépechas contradice esta observación. Su presencia obedece a la necesidad de marcar con elementos específicos la sucesión de los enunciados, revelando así el papel organizador de estos elementos en los niveles sintáctico, enunciativo, lógico y cronológico. 


\section{B. El infinitivo narrativo}

El infinitivo narrativo ha sido mencionado por diferentes autores que han estudiado la lengua purépecha (Foster, 1969: 57; Friedrich, 1984: 59 y 73; Wolf, 1989: 204) sin que ninguno lo haya analizado. En general, en purépecha el infinitivo tiene ciertos comportamientos semejantes a lo que tradicionalmente se conoce como infinitivo, sin embargo presenta también ciertas peculiaridades, en especial la de fungir como núcleo sintáctico. Esta presentación tiene como meta dar cuenta de las características del infinitivo en purépecha. En primer lugar, introduzco la noción de núcleo sintáctico (NS), en segundo lugar, analizo los contextos de aparición del infinitivo y, finalmente, estudio el papel del infinitivo cuando funciona como NS de un enunciado. El infinitivo cumple con esta función solamente en relatos, cuentos, narraciones y leyendas.

\section{a) La noción de núcleo sintáctico}

Antes de abordar plenamente el estudio del infinitivo en general y del infinitivo narrativo en particular, quisiera ofrecer un panorama de la noción de núcleo sintáctico en purépecha. En el nivel de la jerarquía sintáctica, se presenta como el núcleo relacional alrededor del cual se organizan las otras unidades. Es el elemento indispensable e irreductible del enunciado. El NS no pertenece a una clase de unidades en particular, ya que no existe una relación exclusiva entre NS y clase de unidades (Chamoreau, 2000: 135-147). Aunque podemos observar que una gran parte de los NSs son verbales (los elementos de esta clase presentan una vocación específica para operar como NS), existe también la posibilidad de que los nominales ejerzan ese papel. En purépecha, un nominal que desarrolla el papel de NS está acompañado del elemento $i$ (aparece como $e$ en algunas variantes dialectales). Diferentes unidades pueden cumplir el papel de NS: sustantivos, nombres propios, pronombres personales, demostrativos, posesivos, interrogativos, adjetivos, cardinales, cuantificadores, indefinidos y algunos adverbios, por ejemplo:

(1) né $\quad$-i $\quad-\int \quad$-ki - ri

quién+pred. +aor.+int. +2

¿Quién eres? 
(2) wáp ${ }^{\text {ha-i }} \quad-\int \quad$-ka $\quad$-ni páblu-iri

hijo +pred.+aor.+aser.1/2+1 Pablo +gén.

Soy el hijo de Pablo.

(T19) ka tsima tsima -nki anapu $-\mathrm{e} \quad$-ka

y dem.pl. dem.pl.+sub. originario+pred.+subj.

y aquéllos, aquellos que son originarios de abí

(T41) tsirini ima -e $-\mathrm{s}$-ti ima -nki xuka-ka xutfari kwérpu-tu costilla dem.+pred.+aor.+aser.3 dem.+sub. tener+subj. pos.1pl. cuerpo +loc. la costilla es lo que tiene nuestro cuerpo

En algunos dialectos se presenta en ciertos contextos el verbo xinte 'ser', que funciona como una unidad independiente, por ejemplo el enunciado (2) se manifiesta como:
(3) xinte- $\int \quad$-ka -ni wáp ${ }^{\text {ha }}$ páblu-iri
ser +aor.taser.1/2+1 hijo Pablo +gén.
Soy el hijo de Pablo.

La diferencia principal entre los NS verbales y NS nominales es por una parte, la imposibilidad de los segundos de ser determinados por los modos imperativo y exclamativo y por los aspectos progresivo, habitual y continuativo, y por otra parte, la posibilidad de conservación de algunas determinaciones nominales, como el número:
(4) tsitsiki-it $\int a-e \quad-s \quad$-ti $\quad$-ksi
flor +pl. +pred.+aor.+aser.3+3pl.
Son flores.

Además de los verbos y de los nominales, los infinitivos cumplen con la función de NS. Cuando el infinitivo funciona como NS aparece sin marcas de tiempo, de aspecto o de modo, sin embargo cumple con su papel de núcleo organizador del enunciado, obligatoriamente determinado por el sujeto:

(T28) ima ari -ni ya

dem. decir+inf. ya

aquél dice abora 
b) Los contextos de aparición del infinitivo en purépecha

En este apartado se presentan los diferentes contextos de aparición de un infinitivo sin limitarse a un género en particular. Tradicionalmente en purépecha, el infinitivo se manifiesta como una unidad compleja que se forma a partir de la base verbal a la cual se agrega la marca $-n i$, por ejemplo:

(T2) ari-ni 'decir'

(T6) pá-ni 'llevar'

(T10) únta-ni 'empezar'

El infinitivo tiene un funcionamiento particular en el sentido de que aparece en algunos contextos en los cuales generalmente se encuentran los términos que se clasifican como nominales (sustantivos, pronombres personales, posesivos y demostrativos en particular) y en otros contextos en los cuales se presentan los verbos. Dicho de otra manera, es un complejo que ofrece algunas particularidades del funcionamiento del sustantivo y otras del funcionamiento del verbo (Chamoreau, 2000: 271-272)

El infinitivo cumple con algunas funciones en las cuales generalmente aparecen los nominales. Se presenta como sujeto de un verbo (5) y como atributo de un nominal que funciona como NS (6):

(5) xaroa -ni kánikwa sési xara - $\int$-ti

ayudar+inf. muy bien estar +aor.+aser.3

Ayudar está muy bien.

(6) nira-ni $\quad$ i $\quad$-i $\quad-\int \quad$-ti sáni warini

ir +inf. dem.+pred.+aor.+aser.3 poco morir

Irse es morir un poco.

El infinitivo funciona también como objeto de un NS; en el relato existen diferentes ejemplos en los cuales el NS es un verbo conjugado. Podemos observar los enunciados (T6), (T7), (T39) y (T40), por ejemplo:

(T6) ima -nki wéka -ka pá -ni dem. + sub. querer+subj. llevar+inf. el que quiere llevar 
El infinitivo aparece también como objeto de un NS, que se manifiesta como un infinitivo narrativo, por ejemplo después de únta 'empezar' (T10) y (T30) o después de $k^{b} a m a$ 'terminar' en los enunciados (T32) y (T35). Por ejemplo:

(T35) ka khama -ku -ni wara-ni

y terminar+3obj. +inf. bailar+inf.

y terminan de bailar

Los infinitivos aparecen también en contextos en los que esperaríamos un verbo conjugado. Pueden ser determinados por un objeto nominal, maria en el enunciado (7). El nominal está relacionado al infinitivo por el objeto marcado por $-n i$, homófono del -ni infinitivo:

(7) xaroa -ni maria-ni kánikwa sési xara - -ti $^{\text {wa }}$

ayudar+inf. Maria +obj. muy bien estar +aor.+aser.3

Ayudar a María está muy bien.

La marca de objeto puede estar incluida en el infinitivo: en el ejemplo (8), la unidad $-a$ es un objeto de tercera persona del plural:

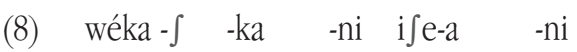
querer+aor.+aser.1/2+1 ver+3pl.obj. +inf.

Quiero verlos.

Existen frases infinitivas introducidas por la preposición pára, tomada del español. En estas frases que expresan la meta, el núcleo es siempre un infinitivo. En el relato, se presentan varios ejemplos: (T16), (T31), (T34), (T36), (T59), (T70) et (T82).

(T34) pára tsa wara-ni ya

para dem.pl. bailar+inf. ya

para que ellos bailen

Paul Friedrich (1984: 73) indica la presencia del infinitivo en frases introducidas por ántede 'antes de'. Este préstamo no aparece en la variante que estudio.

Por otro lado, existen también construcciones complejas formadas por el infinitivo y por el auxiliar xara 'estar'. Generalmente en estos tipos de construcciones se 
encuentran dos de los participios existentes en purépecha. El participio formado con -tini indica el resultado de una acción, por ejemplo:

(9) $\mathrm{i} \quad \mathrm{t}^{\mathrm{h}}$ irerak $\mathrm{k}^{\mathrm{w} a} \quad \mathrm{k}^{\mathrm{w}} \mathrm{ara}$-ta - tini xara- $\int \quad$-ti

dem. mesa fracturar+caus.+part. estar+aor.+aser.3

Esta mesa está rota.

Existe otro participio formado con -kata, que se utiliza en construcciones pasivas (calcadas del español) por ejemplo:

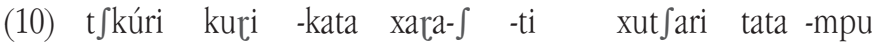
madera quemar+part. estar+aor.+aser.3 pos.1pl. padre+inst. La madera es quemada por nuestro padre.

El infinitivo con el auxiliar xara ofrece un valor aspectual de progresivo y sigue el mismo orden de construcción que los participios con el auxiliar: el infinitivo o el participio están siempre antepuestos al auxiliar xara. Se puede observar en el relato varios enunciados: (T2), (T49), (T78) y (T79). Por ejemplo:

(T78) ka xima thire -ni xara-ti

y allí comer+inf. estar+aser.3

$y$ allí están comiendo

En síntesis, podemos observar que el infinitivo comparte algunos rasgos con el substantivo, otras con el verbo y con el participio. Estos rasgos nos pueden conducir a clasificarlo como una forma 'verbo-nominal' o una forma 'nominal del verbo', que participa de las dos grandes clases de unidades. Aunque tiene algunas similitudes con las unidades de estas clases, presenta diferencias. Por ejemplo, no puede recibir la determinación del plural como los sustantivos, ni la de tiempo, aspecto y modo, como sí pueden hacerlo los verbos.

El infinitivo puede clasificarse como un parasintema (Clairis, 1991), es decir, como un complejo en el cual no es posible determinar individualmente las diferentes partes que lo componen; y a nivel sintáctico presenta ciertas compatibilidades que obligan a ubicarlo en una clase diferente. 
c) El infinitivo narrativo

Los NSs que se manifiestan con una forma de infinitivo narrativo aparecen en los relatos, cuentos, narraciones, leyendas, etc. (Chamoreau, 1997: 271-290; Chamoreau, 2003a; Chamoreau, en prensa; Monzón, 1998: 468-504; Villavicencio, 1992, 2001: 652-658). Según los textos, la proporción de los NSs infinitivos varía entre 30 y $60 \%$ de los NSs del texto. La presencia de NSs nominales es baja, fluctúa entre 2 y 10 \% y en consecuencia la proporción de NSs verbales es la más alta, dependiendo de los textos, oscila entre 40 y $70 \%$. Pese a que los infinitivos narrativos pueden aparecer en cualquier parte del texto, su distribución no tiene un patrón definido. En algunos relatos ocurren de manera equilibrada en las diferentes partes de éstos (Chamoreau, 1997: 271-290), en cambio en otros aparecen solamente en la segunda mitad (Chamoreau, 2003a) o en la parte central, o sea en los 2/3 del texto (como en el Encuentro del tabardillo). El infinitivo narrativo se presenta en todos los contextos, ya sea en la narración o en los diálogos, y con cualquier tipo de verbo (de estado, de comunicación, de acción, etc.). Por ejemplo, en el texto titulado Relato de vida del Sr. Francisco Rita, presentado por Cristina Monzón, podemos encontrar los verbos siguientes: wérbukuni 'salir de la orilla', arbini 'decir', wakórbimuninha 'caerse', manárani 'temblar', jámani 'estar', yót'akuarbintsani 'estirarse'. En el texto presentado por Frida Villavicencio, llamado El Dios de la Lluvia, aparecen: uni 'poder', k'uanhapatsini 'devolverse', andanguni 'alcanzar', pakarani 'quedarse', arbini 'decir', tanguarbintani 'reunirse', etc. ${ }^{5}$ En el presente relato encontramos: úntani 'empezar', nirani 'ir', arini 'decir', xupikani 'agarrar', xamani 'andar', kústani 'tocar un instrumento', etcétera.

En el nivel semántico, el uso del infinitivo realza el significado de los términos y contribuye a una mayor coherencia del relato. En el nivel sintáctico, el hecho de omitir las marcas aspecto-modo-temporales manifiesta una estrategia de economía sintáctica.

En la mayoría de los relatos, el infinitivo narrativo aparece en contextos asertivos (en frases principales o subordinadas); sin embargo, como lo mencionan Foster (1969: 57), Friedrich (1984: 73) y de Wolf (1989: 204), existen casos de infinitivos en contextos imperativos. Esta utilización es particular y reconocible porque se presenta en el contexto de diálogo dentro del relato. Por ejemplo (Chamoreau, en prensa):

\footnotetext{
${ }^{5}$ Respeto aquí la transcripción de las autoras.
} 


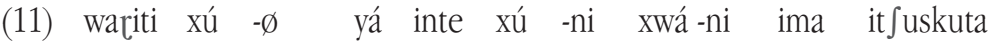
mujer venir+imp.2 ya 'este' venir+inf. traer+inf. dem. tortilla Mujer, ven ya, este, ven, trae esta tortilla

Podemos encontrar otro ejemplo en Villavicencio (2001: 657-janikua 020):
(12) ni- $\varnothing \quad$ orhepa-nta-ni
ni- $\varnothing \quad$ orepa $\quad$-nta -ni
ir+imp. adelantarse+iter.+inf.
Ve, corre por delante (adelántate).

De manera general, un texto presenta NS verbales con marcas aspecto-temporales diferentes. Por ejemplo, el texto que vamos a ver a continuación presenta un marco aspectual habitual. Los primeros NSs verbales están determinados por el aspecto habitual, el cual está presente a todo lo largo del relato. El uso del habitual como marco aspectual narrativo permite al narrador enfatizar el aspecto tradicional, repetitivo, habitual del acontecimiento, prescindiendo de toda referencia al tiempo. En este marco, sobresalen algunas acciones puntuales que también se realizan de manera habitual, pero que el narrador particulariza empleando solamente el asertivo. El uso del modo asertivo sin marca de tiempo ni de aspecto se puede interpretar como un presente. Existe una diferencia entre el uso del habitual, que garantiza a este relato un marco narrativo, y el uso del asertivo solo, que particulariza ciertos procesos, el uso de uno u otro revela una estrategia narrativa. Esta diferencia permite al narrador 'jugar' entre el aspecto y el tiempo para un mismo verbo: por ejemplo, en (T18), (T42) y (T64), el verbo wara 'bailar' aparece con el modo asertivo; en cambio en (T66) y (T71) se presenta con el habitual. De igual manera cuando se trata del canto de los pastores, se puede expresar con el asertivo en (T17) o con el habitual en (T65). Con esta diferencia, el narrador puede expresar dos puntos de vista diferentes: por una parte puede insistir en el hecho de que el bailar y el cantar forman parte de este acontecimiento (aspecto habitual) y, por otra parte, puede hacer énfasis en la realización de la acción en un momento dado, insistiendo sobre la noción de tiempo (modo asertivo).

En el relato que estamos analizando se pueden observar además dos verbos determinados por el futuro (T30) y (T59) y uno por el aoristo (T85). Los primeros indican acciones que se realizarán posteriormente en relación con el proceso que sirve de referencia. El verbo con aoristo enfatiza el hecho de que la acción concluye en el momento de referencia. En resumen, el marco aspecto-temporal de este 
relato es esencialmente habitual y contiene verbos en presente que sirven para contrastar e indicar procesos puntuales.

Los NSs en infinitivo pueden aparecer en cualquier contexto aspecto-temporal, sin que la ausencia de marcas aspecto-temporales obstaculice la comprensión de esos enunciados, ya que en el nivel semántico y pragmático existe por un lado una correlación entre los NSs, y por otro lado, una coherencia de los participantes (procedimientos anafóricos), así como de las diferentes partes del relato (Chamoreau, en prensa). Sin embargo, el co-narrador recurre a estrategias particulares para compensar la ausencia de las marcas. El co-narrador busca en primera instancia hacer correlaciones entre los NSs infinitivos y los NSs verbales del texto. Esta estrategia intratextual puede dividirse, por un lado, en referencia cercana, contextual - cuando los NSs verbales anteceden de manera inmediata al infinitivo narrativo-, y por otro lado, en referencia textual, en la cual la referencia no es cercana sino textual, en este caso la reconstrucción de las marcas ausentes utiliza NSs verbales anteriores relacionadas de manera semántica y no espacialmente directa. No obstante, estas estrategias no siempre permiten la interpretación de algunos infinitivos narrativos. En estos casos, generalmente para los verbos que tienen un estatuto particular en un relato, como son los verbos de comunicación, el co-narrador utiliza estrategias extratextuales, o sea a su propio conocimiento de la lengua.

\section{La estrategia contextual o puntual}

En muchas de sus ocurrencias, los infinitivos narrativos se pueden interpretar en el nivel aspecto-temporal, estableciendo una relación entre el infinitivo y las marcas aspecto-temporales del NS verbal que lo precede. El infinitivo se encuentra en un contexto que es suficiente para su interpretación. Tal es el caso del primer infinitivo narrativo que aparece en (T10):

(T10) ka úntani ánk $k^{\mathrm{h}}$ pastori arikuni

$$
\begin{aligned}
& \text { ka únta -ni ánk } k^{\mathrm{h}} \mathrm{u} \text { pastori ari -ku -ni } \\
& \text { y empezar+inf. entonces pastor decir+3obj.+inf. } \\
& \text { y empiezan entonces a cantar los pastores }
\end{aligned}
$$

El verbo que precede está determinado únicamente por el asertivo, expresando un valor de presente; el infinitivo úntani se puede entender con el mismo valor: sobresale del marco general del relato al habitual porque permite enfatizar una 
acción en particular. Por otra parte, los infinitivos narrativos que aparecen en (T15) y (T16) se relacionan con el núcleo verbal que antecede (T15), que está en habitual:

(T15) ka kínse díya xamasintikst pastori arírani yámintu ireta

ka kínse díya xama-sin -ti -ksì pastori arí -ra -ni yámintu ireta y quince día andar+hab.+aser. $3+3$ pl. pastor decir+caus.+inf. todo pueblo y durante quince dias, los pastores andan, tocan en todo el pueblo

(T16) pwértaet $\int a$ pákt $\int a k u a n i$ pára úni int $\int a k u n i$ pwérta-et $\int a$ pákt $\int a-k u \quad$-a $\quad$-ni pára ú $\quad$-ni int $\int a-k u$-ni puerta +pl. empujar+3obj.+3pl.obj.+inf. para poder+inf. entrar+3obj.+inf. empujan las puertas para poder entrar

En el nivel enunciativo, los tres NSs de (T15) y (T16) se presentan unidos en un marco aspectual: son las acciones que se hacen habitualmente durante estos quince días. Esta unión enunciativa se manifiesta en el nivel sintáctico con una correlación aspectual: los tres pueden entenderse como habitual. Los casos de estrategias contextuales son los más frecuentes porque permiten un anclaje del infinitivo narrativo a su entorno inmediato. La relación sintáctica de los diferentes NSs es directa. Esta interpretación directa se caracteriza por su relatividad porque depende del contexto de aparición del infinitivo narrativo. Representa una economía de interpretación para el co-narrador y una garantía de comprensión entre el narrador y el co-narrador. La alta frecuencia de esta estrategia se puede explicar también por el hecho de que la mayoría de los infinitivos narrativos aparecen solos, es decir intercalados entre dos NSs verbales. El relato El encuentro del tabardillo contiene veintidós infinitivos narrativos de los cuales trece (o sea 55\%) aparecen entre dos verbos. Los otros forman tres cadenas: una de dos infinitivos narrativos (T15-T16), otra de tres (T46-T47-T48), y finalmente una cadena más larga de cinco infinitivos narrativos (T30 a T36). Tanto la cadena de dos como la de tres infinitivos narrativos pueden ser interpretadas con una estrategia contextual.

El caso de la cadena de cinco infinitivos narrativos es distinta, ocurre en un contexto postdiálogo. Por eso mismo es difícil correlacionar estos infinitivos narrativos con los NSs del diálogo, ya que éstos tienen valores aspectuales y modales particulares (imperativo en T27, habitual y futuro en T29). En el nivel enunciativo, el enunciado (T30) inicia una nueva unidad temática. La reconstrucción tiempoaspectual requiere de otra estrategia. 


\section{La estrategia textual o global}

El segundo tipo de estrategia se distingue también por su carácter relativo, es decir, que se sitúa dentro del texto, sin embargo necesita un rastreo más amplio que la estrategia contextual, vista como puntual. Aquí se oponen, por un lado el contexto visto como una parte del texto, entendido éste como un todo. La estrategia textual, vista como global, implica el conocimiento general del texto (de la parte que ya fue narrada), la distinción y la correlación de sus diferentes partes.

Para reconstruir la información aspecto-temporal de estos infinitivos narrativos, se necesita relacionarlos con NSs verbales que no se encuentren directa y espacialmente cercanos. En este texto, varios infinitivos narrativos aparecen después de verbos que presentan un aspecto o un tiempo que no permite la interpretación del infinitivo. En el relato existen varios ejemplos de infinitivos que no se pueden interpretar utilizando el verbo que los precede, por ejemplo: úntani 'empezar' en (T30) y $k^{b}$ amakuni 'terminar' en (T32) y en (T35):

(T30) ka tsa úntani músikuet $\int a$ kústani ya

$$
\begin{aligned}
& \text { ka tsa únta -ni músiku-et } \int a \text { kústa-ni ya } \\
& \text { y dem.pl. empezar+inf. músico +pl. tocar +inf. ya }
\end{aligned}
$$

(T32) ka khamakuni tsa pastori arini ya

ka khama -ku -ni tsa pastori ari -ni ya

y terminar+3obj.+inf. dem.pl. pastor decir+inf. ya $y$ estos pastores terminan de hablar

(T35) ka khamakuni warani

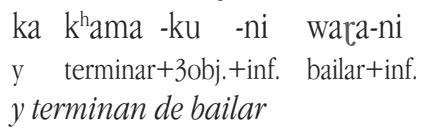

Estos infinitivos aparecen después de un verbo determinado por el habitual, sin embargo su inserción en este texto implica una interpretación que hace énfasis en la temporalidad. La unidad enunciativa que empieza en (T30) rompe con lo que precede, no se puede relacionar con el diálogo (T27 a T29). El diálogo tiene su propio funcionamiento aspecto-temporal, el cual se diferencia del relato. La imposibilidad de relacionar estos infinitivos narrativos con los verbos cercanos obliga 
al co-narrador a construir una red de relaciones que se expande al texto de manera global. Existe una correlación semántica entre úntani que aparece en (T30) y $k^{b}$ amakuni 'terminar' en (T32) y en (T35) con úntani en (T10) o con $k^{b} a m a r a n i$ que se presenta en (T49). Esta relación semántica (entre unidades de misma significación) implica, en este texto y por estos NSs, una correlación aspecto-temporal. En (T10) y (T49), úntani y $k^{b} a m a r a n i$ aparecen determinados por el modo asertivo, el cual pone a la luz un cambio de acción y de tema introducidos por estos verbos. En (T30), (T32) y (T35), los infinitivos narrativos funcionan con el mismo proceso.

El co-narrador necesita anclar su interpretación en la cohesión del texto. Las marcas que le permiten reconstruir la información aspecto-temporal no aparecen en el contexto inmediato del NS en infinitivo, sino que están contenidas previamente en el texto. Por lo tanto, el narrador emite la hipótesis de una comprensión compartida de este mensaje a partir del conocimiento del texto. Se trata de una reconstrucción de la información a partir de datos narrativos incluidos en el texto mismo. Existe entonces una cooperación activa entre el narrador y el co-narrador para la construcción del significado del texto. El co-narrador se apoya en la significación de los otros NSs y en las relaciones que construyen entre ellos. Esta segunda estrategia permite el desarrollo de la coherencia y de la cohesión textual y de la búsqueda intratextual.

\section{La estrategia extratextual}

La última estrategia empleada se basa en los conocimientos lingüísticos del conarrador. En ésta, el co-narrador reconstruye la información a partir de sus propios conocimientos de la lengua purépecha y de las particularidades del género narrativo. Éstos le permiten saber que en los relatos, ciertos procesos que aparecen con la forma de infinitivos narrativos, se pueden reconstruir siempre (o casi siempre), con el tiempo-aspecto que sirve de base (aquí el habitual) o con el aspecto que se usa con frecuencia en un relato para expresar los eventos, el aoristo. Los NSs que entran en este grupo presentan una característica semántica común, todos introducen o concluyen un diálogo, son verbos de comunicación, como 'decir', 'gritar', 'hablar', etc. En este texto se presentan tres ocurrencias, se trata siempre del mismo término: arini 'decir' (T26), (T28) y (T37). 
(T26) ka ménteruksini arini

ka ménteru-kstni ari -ni

y otra vez +3 pl.obj. decir+inf.

otra vez les dicen

(T28) ima arini ya

ima ari -ni ya

dem. decir+inf. ya

aquél dice ahora

(T37) ka meyamuati ya ka arini
ka meya-mu -a -ti
y trocar+z.oral+3pl.obj.+aser.3 ya y decir+inf.
ya les pagan y dicen

Sea cual fuere el contexto en el que se presenta este infinitivo narrativo, el narrador y el co-narrador saben que esta unidad trae una información particular, sirve para introducir o concluir un diálogo. En la mayoría de sus ocurrencias, su interpretación no necesita referirse al texto, es extratextual. Presenta un carácter absoluto, fuera de una interpretación textual y anterior a cualquier existencia del texto. El conocimiento de la lengua y de las particularidades de la narración son suficientes. Por el momento, mi análisis permite incluir solamente los verbos de comunicación en esta tercera estrategia, sin embargo, es posible que en estudios futuros se encuentren otros tipos de verbos.

Las tres estrategias antes mencionadas se pueden clasificar en dos ejes, las dos primeras, que se presentan de manera puntual o global, se caracterizan como relativas porque están ancladas en un relato particular y necesitan del relato, en tanto que la tercera se caracteriza como absoluta, ya que existe fuera de cualquier texto y se basa en un conocimiento previo de la lengua y de la narrativa purépecha. El uso de NSs en infinitivo entra en el marco de la economía sintáctica, en la cual ciertos elementos pueden ser omitidos porque esta ausencia se puede subsanar gracias a la información contenida en el texto y al conocimiento lingüístico.

Estas tres estrategias se complementan e interactúan. Participan de la cooperación del narrador y del co-narrador para transmitir y construir-reconstruir un relato. La presencia de los NSs infinitivos es una característica narrativa cuyo conocimiento es compartido por todos los hablantes de purépecha. Por eso, la comunidad lingüística comparte una connivencia que se basa en su conocimiento de la lengua y de 
los procedimientos narrativos que se pueden aplicar en un género en particular. La comunicación y la comprensión se basan en esta construcción-reconstrución de la información a través de los sistemas lingüístico y narrativo de los hablantes.

TEXTO

TAKARI KÚNTS ${ }^{\mathrm{H}} \mathrm{HA}$

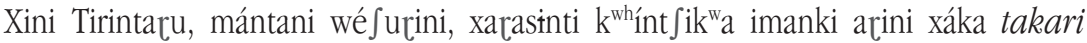
kúnts ${ }^{b} \dot{t k a}$. Kaksi xini, iretaru, wétastnti ya tatani, imani petanastnti ya. Péerasinti ma ojo kumant $\int i k^{w} a r u$ imanki wékaka páni, imanki wékaka gastarini. Siempri ojo gastarikurisinti sáni, ka ima nyárati ya.

Ka úntani ánk $k^{\mathrm{h}} \mathrm{u}$ pastori arikuni, kustatiet $\int a$ ka thareet $\int a$ ka maringyet $\int a$ ka wátsi

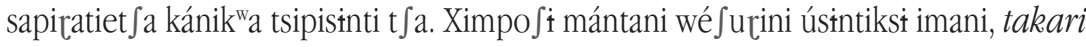

ojo arikata. Ka kínse díya xamasintiksi pastori arírani yámintu ireta, pwertaet $a$

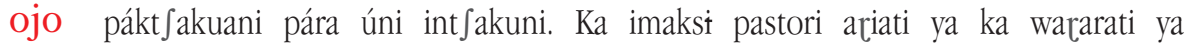
$t^{\text {thareet } \int a n i ~ k a ~ m a r i n g y a e t \int a n i . ~ K a ~ t s t ́ m a ~ t s ́ m a n k i ~ a n a p u e k a, ~ a t \int a m a s i ~ o ~ w a r i m a s i ́, ~}$ intsasintiksì imanki arika ya: tét $\int a k^{\mathrm{w}} a$ ka wiraterakª ka sáni tsíri o sáni xapumata o wanita o ampe imanki xatsiaka. Imani íntskustnti ya.

Ka ménteruksini arini: 'Yásı ampe arii t $\int a$.'

Ima arini ya: 'Yásí wékastnka íski pastoriet 〔a ariaka ya.'

Ka tsa úntani músikuet $\int a$ kústani ya, ka tsa para pireni ya thareet $\int a$ ka marin-

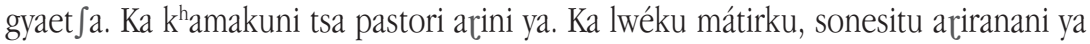
pára tsa warani ya. Ka khamakuni warani, ka méntiruksi nirani ya pára meyamuani méntiru.

Ka meyamuati ya ka arini: 'Yásł ampe t $\int a$ wékastni?'

'Yási wékastnka tsirini warani tsirini ka tsa lwégu músikuet $\int a$ kústani.'

Tsirini imaesti imanki xukaka xut 〔a kwérpuru ka warati ma thámu yúmu wuélta.

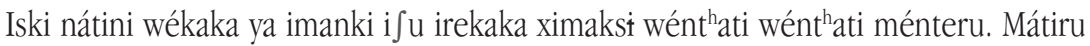

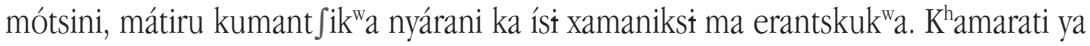
ánk ${ }^{\mathrm{h}} \mathrm{u}$ posada imanki xini úni xáka tyósto ka i $\mathrm{u}_{\mathrm{u}}$ wérak $^{\mathrm{w} a t^{\mathrm{h}}} \mathrm{u}$. Ka nirani ya, kókani xamati ya. Ank $k^{\mathrm{h}} u$ ma tarola ánk $k^{\mathrm{h}} \mathrm{u}$ ma karisu ma arirakata kústani. Ka xima xamati

ojo ya, Janari kústani tsimani $k^{\text {wh }}$ iripuet $\int a$. Ka méntiru músika, tóro arikata kústastntikst ya.

Ka ménteruksi ampokuta xupikani pára eyampini ya íski niaka ya xini, xini takari xwákunikst. Nirani xanarikutini, mekantani ánk $k^{\mathrm{h}} \mathrm{u}$ Janaru kamyoniet $\int a$ xatakwa ka 


\section{TRADUCCIÓN}

\section{ENCUENTRO DEL TABARDILLO}

Allá en Tiríndaro, cada año, hay una fiesta que se llama el Encuentro del tabardillo. Allá, en el pueblo, sacan al Niño Dios. Lo lleva a una casa el que quiere llevarlo y el que quiere gastar. Siempre se gasta un poco.

Cuando éste llega, entonces empiezan a cantar los pastores, los músicos, los viejos, las maringuias. Los niños pequeños están muy felices. Por eso, cada año hacen ésto, el llamado tabardillo. Durante quince días, los pastores andan, tocan en todo el pueblo, empujan las puertas para poder entrar. Los pastores cantan y hacen bailar a los viejos y las maringuias. Los que son originarios de ahí, los hombres o las mujeres, les dan lo que dicen: el vino y el alcohol y un poco de maíz o un poco de pinole o esquite o lo que tienen.

Otra vez les dicen: 'Ahora, canten ustedes'

Aquel dice: 'Ahora, queremos que los pastores canten'.

Los músicos empiezan a tocar, para que los viejos y las maringuias canten. Los pastores terminan de cantar. Luego repentinamente se interpretan los sonecitos para que bailen. Terminan de bailar y se van otra vez para que les paguen de nuevo.

Cuando les pagan, dicen: 'Ahora ¿qué quieren ustedes?'

'Ahora, queremos las costillas, que las costillas bailen y después que los músicos toquen'.

La costilla es lo que tiene nuestro cuerpo y bailan una, cuatro, cinco vueltas. Cuando lo quiere el que vive aquí, salen y salen otra vez. Cambian de casa, llegan a otra casa y así andan toda la noche. Ya se termina la posada en la iglesia afuera. Después, se van, andan rápido. Entonces, tocan la tarola, la flauta de carrizo, una pieza de música. Andan en el camino, dos personas tocan un instrumento. Y otra vez tocan el Toro.

Otra vez agarran la calle para anunciar que irán allá, allá de donde traen el tabardillo. Van al lado del camino, de los camiones y de los medios de transporte y van allí a las once horas. Y allá bailan y los músicos interpretan el Toro. Bailan y 
nirati ya xima témpini ka ma atakwaru. Ka xinisi warati ya ka tóru úkuriti ya, ka músikuet $\int a$ tóru arirasinti ya. Xima waranasinti ya, ka ximaksł tsíri tiripani. Ka ménk ${ }^{\mathrm{h}} \mathrm{a}$ ánk $\mathrm{h}^{\mathrm{h}} \mathrm{k}$ kolasyon ístk ${ }^{\mathrm{h}} \mathrm{u} \mathrm{k}^{\mathrm{wh}}$ anikuni: naran $\int a$ ampe stmpa ampe t $\int a ́ p a t a$, pára xak ${ }^{\mathrm{h}}$ ani úni t tápata.

Xima waranasinti ya, ka ménteru wantstkurinati ya. Tóro arikurini méntiru

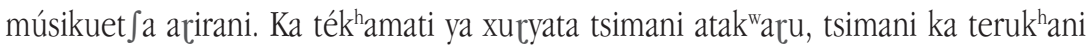
atak"waru. Ka nyánthati méntiru xini ireta, xini náni tátaníno xarati ya. Ka xima thireni xarati ka méntiru xima warani xarati.

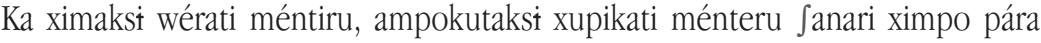

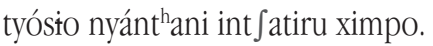

ojo Ke ísł nyánt haka xima, táta wérasinti ya út ${ }^{\text {hakaraani yámintuet } \int a n i . ~}$

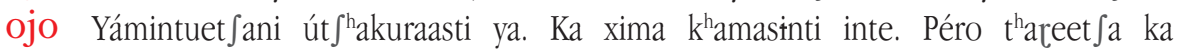
maringyaet $\int a$ mentiru xuryata ximpo xamastntiksi xima khamasinti ya ásta wé $\int u$ rini. 
cuelgan el maíz. Siempre tiran así la colación: naranjas, cañas, tamales, para entonces hacer los tamales.

Bailan, otra vez se dan vueltas. Se llama el Toro, los músicos lo interpretan otra vez. Cuando el Sol pasa el cenit, son las dos de la tarde, las dos y media. Regresan allá al pueblo, allá, donde está el Niño Dios. Comen y bailan otra vez. Salen otra vez, agarran la calle, en el camino para llegar a la iglesia en la tarde. Cuando llegan allí, el sacerdote sale y bendice a todos. Los bendice a todos. Esto se termina allí. Pero los viejos y las maringuias caminan otra vez con el Sol y allí se termina hasta el próximo año. 


\title{
ANÁLISIS MONEMÁTICO
}

\author{
takari kúntshìka \\ tabardillo encuentro \\ el encuentro del tabardillo
}

1. xini Tirintaru mántani wé $\int u$ urini

xini Tirintaru mántani wé Surini

allá Tiríndaro cada año

allá en Tiríndaro cada año

2. xarasinti $\mathrm{k}^{\text {wh }}$ ínt $\int i k^{\mathrm{w}} \mathrm{a}$ imanki arini xáka

xara-sin -ti $\quad k^{\text {whínt } \int i k^{w} a}$ ima -nki ari -ni xá -ka

estar+hab.+aser.3 fiesta dem.+sub. decir+inf. estar+subj.

bay una fiesta que está llamada

3. takari kúntsh $\mathrm{kka}$

takari kúntshika

tabardillo encuentro

el encuentro del tabardillo

4. kaksì xini iretaru wétasinti ya tatani

ka-ksi xini ireta -ru wé -ta -sin -ti ya tata -ni

y +3 pl. allá pueblo+loc. salir+caus.+hab.+aser.3. ya hombre+obj.

y allá, en el pueblo, sacan ya al señor (Niño Dios)

5. ima petanastnti ya

ima-ni peta-na -sin -ti ya

dem.+obj. sacar+interior-act.+hab.+aser.3 ya

lo sacan ya (del interior de un lugar)

6. péerasinti ma kumant $\int i k^{w} a r u$ imanki wékaka páni

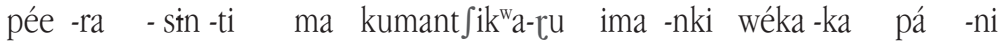
llevar+caus. +hab.+aser.3 un casa +loc. dem.+sub. querer+subj. llevar+inf. lo lleva a una casa el que quiere llevar 
7. imanki wékaka gastarini

ima -nki wéka -ka gastari-ni

dem.+sub. querer+subj. gastar +inf.

el que quiere gastar

8. siempri gastarikurisinti sáni

siempri gastari-kuri-sin -ti sáni

siempre gastar + ref. +hab.+aser.3 poco

siempre se gasta un poco

9. ka ima nyárati ya

ka ima nyára -ti ya

y dem. llegar +aser.3 ya

yéste llega ya

10. ka úntani ánk $k^{\mathrm{h}} \mathrm{u}$ pastori arikuni

ka únta -ni ánk ${ }^{\mathrm{h}} u$ pastori ari -ku -ni

y empezar+inf. entonces pastor decir+3obj.+inf.

y empiezan entonces a cantar los pastores

11. kustatiet $\int a$ ka thareet $\int a$ ka maringyet $\int a$ ka wátsi sapiratiet $\int a$

kustati-et $\int a$ ka thare-et $\int a$ ka maringya-et $\int a$ ka wátsì sapirati-et $\int a$

músico+pl. y viejo + pl. y maringuia + pl. y niño pequeño+pl.

los músicos, los viejos, las maringuias y los niños pequeños

12. kánik"a tsipisinti t $\int a$

kánikwa tsipi $\quad$-sin $\quad$-ti $\quad \mathrm{t} \int \mathrm{a}$

muy estar feliz+hab.+aser.3 dem.pl.

están muy felices

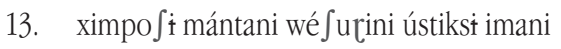

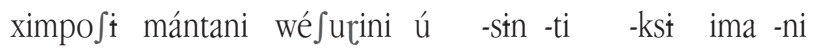

por eso cada año hacer+hab.+aser. $3+3$ pl. dem. + obj.

por eso, cada año bacen ésto

14. takari arikata

takari ari -kata

tabardillo decir+part.

el llamado tabardillo 
15. ka kínse díya xamasintikst pastori arírani yámintu ireta

ka kínse díya xama-sin -ti -ksi pastori arí -ra -ni yámintu ireta

y quince día andar+hab.+aser.3+3pl. pastor decir+caus.+inf. todo pueblo

y durante quince días, los pastores andan, tocan en todo el pueblo

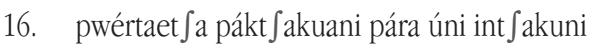

pwérta-et $\int a$ pákt $\int a-k u \quad-a \quad$-ni pára ú -ni int $\int a-k u \quad$-ni

puerta + pl. empujar+3obj.+3pl.obj.+inf. para poder+inf. entrar+3obj.+inf.

empujan las puertas para poder entrar

17. ka imaksì pastori ariati ya

ka ima -ksi pastori ari -a -ti ya

y dem.+3pl. pastor decir+3obj.+aser.3 ya

y aquellos pastores cantan

18. ka wararati ya $t^{\text {h }}$ areet $\int a n i$ ka maringyaet $\int a n i$

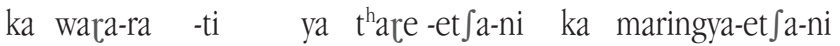

y bailar+caus.+aser.3 ya viejo +pl. +obj. y maringuia + pl. +obj.

y hacen bailar a los viejos y las maringuias

19. ka tsima tsimanki anapueka

ka tsima tsima -nki anapu -e $-k a$

y dem.pl. dem.pl.+sub. originario+pred.+subj.

y aquellos aquellos que son originarios de abi

20. at amasì o warimasi

at $\int a m a s \dot{~} \mathrm{o}$ warimasi

hombre o mujer

los hombres o las mujeres

21. intsastntikst imanki ariska ya

ínts-a -sin -ti -ksí ima -nki ari -ka ya

dar+3pl.obj.+hab.+aser.3+3pl. dem.+sub. decir+subj. ya

les dan lo que dicen

22. tét $\int a k^{w} a$ ka wiraterakwa

tét $\int a k^{w} a$ ka wiraterak ${ }^{w} a$

vino $y$ alcohol

el vino y el alcohol 
23. ka sáni tsíri o sáni xapumata

ka sáni tsíri o sáni xapumata

y poco maíz o poco pinole

y un poco de maíz o un poco de pinole

24. o wanita o ampe imanki xatsiaka

o wanita o ampe ima -nki xatsi-a -ka

o esquite o algo dem.+sub. tener+3pl.obj.+subj.

o esquite o algo que tienen

25. imani íntskusinti ya

ima -ni ínts-ku -sin -ti ya

dem.+obj. dar +3obj. +hab.+aser.3 ya

dan esto ya

26. ka ménteruksini arini

ka ménteru-ksini ari -ni

y otra vez +3 pl.obj. decir+inf.

otra vez les dicen

27. yásí ampe arii t $\int a$

yásł ampe ari -i t $\mathrm{ta}$

ahora algo decir+imp.2pl. 2pl.

abora, canten ustedes

28. ima arini ya

ima ari -ni ya

dem. decir+inf. ya

aquel dice abora

29. yásì wékasinka íski pastoriet $\int a$ a ariaka ya

yásì wéka -sin -ka íski pastori-et $\int a$ ari -a -ka ya

ahora querer+hab.+aser.1/2 sub. pastor + pl. decir+fut. + sub ya

abora, queremos que los pastores canten

30. ka tsa úntani músikuet $\int a$ kústani ya

ka tsa únta -ni músiku-etða kústa-ni ya

y dem.pl. empezar+inf. músico + pl. tocar + inf. ya

y ellos, los músicos ya empiezan a tocar 
31. ka tsa para pireni ya thareet $\int a$ ka maringyaet $\int a$

ka tsa para pire -ni ya thare-et $\int a$ ka maringya-et $\int a$

y dem.pl. para cantar+inf. ya viejo + pl. y maringuia + pl.

para que canten ellos, los viejos y las maringuias

32. ka khamakuni tsa pastori arini ya

ka khama -ku -ni tsa pastori ari -ni ya

y terminar+3obj.+inf. dem.pl. pastor decir+inf. ya

y estos pastores terminan de cantar

33. ka lwéku mátirku

ka lwéku mátirku

y luego repentinamente

y luego repentinamente

34. sonesitu ariranani ya pára tsa warani ya

sones-itu ari -ra -na -ni ya pára tsa wara-ni ya

sones +dim. decir+caus. + pasiv.+inf. ya para dem.pl. bailar+inf. ya

se interpretan los sonecitos para que ellos bailen

35. $\mathrm{ka} \mathrm{k}^{\mathrm{h}}$ amakuni warani

ka khama -ku -ni wara-ni

y terminar+3obj.+inf. bailar+inf.

y terminan de bailar

36. ka méntiruksi nirani ya pára meyamuani méntiru

ka méntiru-ksi nira-ni ya pára meya-mu -a -ni méntiru

y otra vez +3 pl. ir +inf. ya para trocar+z.oral+3pl.obj.+inf. otra vez

y se van otra vez para que les paguen de nuevo

37. ka meyamuati ya ka arini

ka meya-mu -a -ti ya ka ari -ni

y trocar+z.oral+3pl.obj.+aser.3 ya y decir+inf.

ya les pagan y dicen

38. yásł ampe t $\int a$ wékasini

yási ampe t ta wéka -sin -i

ahora que 2pl. querer+hab.+int.

abora, qué quieren ustedes 
39. yásł wékasinka tsirini warani tsirini

yásí wéka -sin -ka tsirini wara-ni tsirini

ahora querer+hab.+aser.1/2 costilla bailar+inf. costilla

abora, queremos las costillas, que las costillas bailen

40. ka tsa lwégu músikuet $\int a$ kústani

ka tsa lwégu músiku-et $\int a$ kústa-ni

y dem.pl. luego músico + pl. tocar +inf.

y luego que los músicos toquen

41. tsirini imaesti imanki xukaka xut $\int a$ kwérpuru

tsirini ima -e $-s$-ti ima-nki xuka-ka xut Jari kwérpu-ru

costilla dem.+pred.+aor.+aser.3 dem.+sub. tener+subj. pos.1pl. cuerpo +loc.

la costilla es lo que tiene nuestro cuerpo

42. ka warati ma thámu yúmu wuélta

ka wara-ti ma thámu yúmu wuélta

y bailar+aser.3 un cuatro cinco vuelta

y bailan una, cuatro, cinco vueltas

43. íski nátini wékaka ya

íski nátini wéka-ka ya

sub. cuando querer+subj. ya

cuando quiere

44. imanki i iu irekaka

ima -nki i $\int u$ ire -ka -ka

dem.+sub. aquí vivir+est.+subj.

el que vive aquí

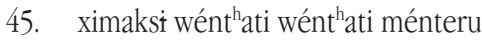

xima-ksi wé -nt ${ }^{\text {ha }}$-ti wé $-n t^{\text {ha }}$-ti ménteru

allí +3pl. salir+centrif.+aser.3 salir+centrif.+aser.3 otra vez

allí, salen y salen otra vez

46. mátiru mótsini

mátiru mó -tsi -ni

otro cambiar+transloc.+inf.

cambian de casa 
47. mátiru kumant $\int i k^{\mathrm{w} a}$ nyárani

mátiru kumant $\int i k^{w a} a$ nyára-ni

otro casa llegar +inf.

llegan a otra casa

48. ka ísł xamanikst ma erantskuk ${ }^{\mathrm{w} a}$

ka ísł xama-ni -ksł ma erantskuk ${ }^{w} a$

y así andar+inf.+3pl. un claridad

$y$ asi andan hasta amanecer

49. $\mathrm{k}^{\mathrm{h}}$ amarati ya ánk $\mathrm{k}^{\mathrm{h}} \mathrm{u}$ posada imanki xini úni xáka tyósto

$k^{\text {hama -ra -ti ya ánk }{ }^{\text {h}} u}$ posada ima -nki xini ú -ni xá -ka tyósi-o

terminar+ref.+aser.3 ya entonces posada dem.+sub. allá hacer+inf. estar+subj. dios +res.

ya se termina la posada lo que se está haciendo en la iglesia

50. ka i $\int u$ wérak ${ }^{\mathrm{w}} a t^{\mathrm{h}} \mathrm{u}$

ka ifu wérak ${ }^{\mathrm{w} a}-\mathrm{t}^{\mathrm{h}} \mathrm{u}$

y aquí afuera también

y aqui afuera también

51. ka nirani ya

ka nira-ni ya

y ir +inf. ya

y ya se van

52. kókani xamati ya

kókani xama-ti ya

rápido andar+aser.3 ya

andan rápido

53. ánk $k^{\mathrm{h}} \mathrm{ma}$ tarola ánk $\mathrm{h}^{\mathrm{h}} \mathrm{ma}$ karisu ma arirakata kústani

ánk ${ }^{\mathrm{h}} \mathrm{u}$ ma tarola ánk $k^{\mathrm{h}} \mathrm{u}$ ma karisu ma arí -ra -kata kústani

entonces un tarola entonces un carrizo un decir+caus.+part. tocar

entonces, tocan la tarola, la flauta de carrizo, una pieza de música

54. ka xima xamati-ya

ka xima xama-ti ya

y allí andar+aser.3 ya

$y$ andan ya allí 


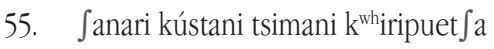

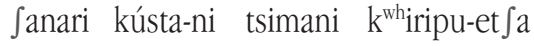

camino tocar + inf. dos persona + pl.

en el camino, dos personas tocan un instrumento

56. ka méntiru músika

ka méntiru músika

y otra vez música

y otra vez la música

57. tóro arikata kústastntikst ya

tóro ari -kata kústa-sin -ti -ksł ya

toro decir+part. tocar +hab.+aser.3+3pl. ya

tocan la pieza el Toro

58. ka ménterukst ampokuta xupikani

ka ménteru-ksí ampokuta xupi -ka -ni

y otra vez +3 pl. calle agarrar+est. + inf.

y otra vez agarran la calle

59. pára eyampini ya íski niaka ya xini

pára eya -mpi -ni ya íski ni-a -ka ya xini

para anunciar+asoc.+inf. ya sub. ir+fut.+subj. ya allá

para anunciar que irán allá

60. xini takari xwákuniksł

xini takari xwá -ku -ni -ksì

allá tabardillo traer+3obj.+inf.+3pl.

allá de donde traen el tabardillo

61. nirani xanarikutini

nira-ni xanarikutini

ir +inf. cuneta

van en la cuneta

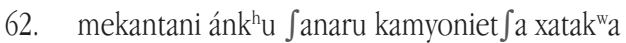

mekantani ánk $k^{\mathrm{h}} \mathrm{u}$ Janaru kamyoni-et $\int a$ xatak ${ }^{\mathrm{w} a}$

lado entonces camino autobus +pl. medio de transporte

entonces al lado del camino, de los camiones y de los medios de transporte 
63. ka nirati ya xima témpini ka ma atakwaru

ka nira-ti ya xima témpini ka ma atakª-ru

y ir taser.3 ya allí diez y un hora +temp

y van alli a las once boras

64. ka xinisì warati ya ka tóru úkuriti ya

ka xini-si wara-ti ya ka tóru ú -kuri-ti ya

y allá +solamente bailar+aser.3 ya y toro hacer+ref. +aser.3 ya

y allá solamente bailan y ocurre el Toro

65. ka músikuet $\int a$ tóru arirasinti ya

ka músiku-et $\int a$ tóru ari -ra -sin -ti ya

y músico + pl. toro decir+caus. +hab.+aser.3 ya

y los músicos interpretan ya el Toro

66. xima waranasinti ya

xima wara -na -sin -ti ya

allí bailar + pasiv. +hab. +aser. 3 ya

alli bailan (se baila)

67. ka ximaksì tsíri tiripani

ka xima-ksì tsíri tiri -pa -ni

y allí +3 pl. maíz colgar+centrif.+inf.

y allí cuelgan el maíz

68. ka ménk $k^{\mathrm{h}} \mathrm{u}$ ánk ${ }^{\mathrm{h}} \mathrm{u}$ kolasyon śt $^{\mathrm{h}} \mathrm{u} \mathrm{k}^{\text {wh }}$ anikuni

ka ménk $k^{\mathrm{h}} \mathrm{a} \mathrm{n}^{\mathrm{h}} \mathrm{u}$ kolasyon ísł - $\mathrm{k}^{\mathrm{h}} \mathrm{u} \quad \mathrm{k}^{\text {whani-ku }}$-ni

y siempre entonces colación asítsolamente tirar +3obj.+inf.

y siempre tiran así la colación

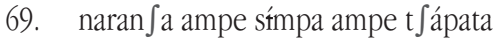

naran Ja ampe st́mpa ampe t tápata

naranja algo caña algo tamal

naranjas, cañas, tamales

70. pára xak ${ }^{\mathrm{h}}$ ani úni t $\int a ́ p a t a$

pára xaknani ú -ni t tápata

para entonces hacer+inf. tamal

para entonces hacer tamales 
71. xima waranasinti ya

xima wara-na -sin -ti ya

allí bailar+pasiv.+hab.+aser.3 ya

allí bailan (se baila)

72. ka ménteru wantsikurinati ya

ka ménteru wantsi -kuri-na -ti ya

y otra vez dar vueltas+ref. + pasiv.+aser.3 ya

otra vez se dan vueltas

73. tóro arikurini méntiru músikuet $\int a$ arirani

tóro ari -kuri-ni méntiru músiku-et $\int a$ ari -ra -ni

toro decir+ref. +inf. otra vez músico +pl. decir+caus.+inf.

se llama el Toro, los músicos lo interpretan otra vez

74. ka ték ${ }^{\mathrm{h}}$ amasti ya xuryata tsimani atakwaru

ka ték ${ }^{\mathrm{h}} \mathrm{a} \quad$-ma -ti ya xuryata tsimani atak ${ }^{\mathrm{w}} \mathrm{a}-\mathrm{ru}$

y pasar el cenit+z.abierta+aser.3 ya sol dos hora ttemp.

y el Sol pasa por el cenit, son las dos de la tarde

75. tsimani ka teruk ${ }^{\mathrm{h}} a n i$ atakwaru

tsimani ka teruk ${ }^{\mathrm{h}} a n i$ atak ${ }^{\mathrm{w}} \mathrm{a}-\mathrm{ru}$

dos y mitad hora +temp.

las dos y media

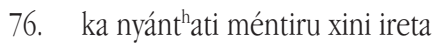

ka nyá -ntha -ti méntiru xini ireta

y llegar+centrif.+aser.3 otra vez allá pueblo

y regresan allá al pueblo

77. xini náni tátaníno xaraski ya

xini náni táta-níno xara-ti ya

allá donde Dios+niño estar+aser.3 ya

allá, donde está el Niño Dios

78. ka xima thireni xarati

ka xima thire -ni xara-ti

y allí comer+inf. estar+aser.3

$y$ allí están comiendo 
79. ka méntiru xima warani xarati

ka méntiru xima wara-ni xara-ti

y otra vez allí bailar+inf. estar+aser.3

y otra vez bailando

80. ka ximaksì wérati méntiru

ka xima-ksi wé -ra -ti méntiru

y allí +3pl. salir+ref.+aser.3 otra vez

$y$ allí, salen otra vez

81. ampokutaksł xupikati ménteru Janari ximpo

ampokuta-ksł xupi -ka -ti ménteru Janari ximpo

calle +3pl. agarrar+est.+aser.3 otra vez camino loc

otra vez agarran la calle, en el camino

82. pára tyósło nyánt $t^{\mathrm{h}}$ ani int $\int a t i r u$ ximpo

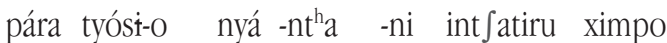

para dios +res. llegar+centrif.+inf. tarde temp.

para llegar a la iglesia en la tarde

83. ke ísł nyánthaka xima

ke ísà nyá -nt ${ }^{\text {ha }}$-ka xima

sub. así llegar+centrif.+subj. allí

cuando llegan allí

84. táta wérasinti ya út $\int^{\mathrm{h}}$ akuraani yámintuet $\int a n i$

táta wé -ra -sin -ti ya ú - t $\int^{\text {ha }}$-ku $\quad$-ra $\quad$-a $\quad$-ni yámintu-et $\int a-n i$

sacerdote salir+ref.+hab.+aser.3 ya tapar+z.estrecha+3obj.+caus.+3pl.obj.+inf. todo +pl. +obj.

el sacerdote sale, bendice a todos

85. yámintuet $\int a n i$ út $\int^{\text {hakuraasti ya }}$

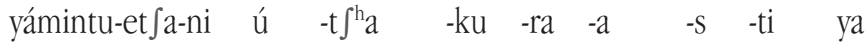

todo +pl. +obj. tapar+z.estrecha +3obj.+caus.+3pl.obj.+aor.+aser.3 ya

ya los bendijo a todos

86. ka xima $\mathrm{k}^{\mathrm{h}} \mathrm{amasinti} \mathrm{inte}$

ka xima $k^{\text {hama }}$-sin -ti inte

y allí terminar+hab.+aser.3 dem.

$y$ ésto se termina alli 
87. péro thareet $\int a$ ka maringyaet $\int a$

péro thare-et $\int a$ ka maringya-et $\int a$

pero viejo + pl. y maringuia + pl.

pero los viejos y las maringuias

88. mentiru xuryata ximpo xamasintiksi

mentiru xuryata ximpo xama-sin -ti $-\mathrm{ksi}$

otra vez sol temp. andar+hab.+aser.3+3pl.

caminan otra vez con el Sol

89. xima k kamastnti ya ásta wé $u$ urini

xima khama -sin -ti ya ásta wé Jurini

allí terminar+hab.+aser.3 ya. hasta año

ya se termina allí hasta el próximo año

\section{Convenciones y abreviaturas}

El acento puede presentarse en la primera o en la segunda sílaba; lo he indicado con un acento agudo en la vocal solamente cuando aparece en la primera sílaba (excepto en las palabras monosilábicas que no ofrecen diversas posibilidades). La transcripción fonológica se hace con el Alfabeto Fonético Internacional, por ejemplo: / $/$ es una retrofleja, /x/ es una fricativa velar, $/ \mathrm{J} /$ es una fricativa palatal, $/ \mathrm{k}^{\mathrm{w}} /$ es una labiovelar, $/ \mathrm{t} /$ es una vocal central de primer grado, etc. La aspiración se indica así $\mathrm{h} /$, por ejemplo $/ \mathrm{p}^{\mathrm{h}} \%$

$\begin{array}{llll}\text { act. } & \text { activo } & \text { obj. } & \text { objeto } \\ \text { aor. } & \text { aoristo } & \text { part. } & \text { participio } \\ \text { aser. } & \text { asertivo } & \text { pasiv. } & \text { pasivo } \\ \text { caus. } & \text { causativo } & \text { pl. } & \text { plural } \\ \text { centrif. } & \text { centrífugo } & \text { pos. } & \text { posesivo } \\ \text { dem. } & \text { demostrativo } & \text { pred. } & \text { predicativizador } \\ \text { estat. } & \text { estativo } & \text { ref. } & \text { reflexivo } \\ \text { fut. } & \text { futuro } & \text { sub. } & \text { subordinante } \\ \text { gen. } & \text { genitivo } & \text { subj. } & \text { subjuntivo } \\ \text { hab. } & \text { habitual } & \text { transloc. } & \text { translocativo } \\ \text { imp. } & \text { imperativo } & \text { z. } & \text { zona } \\ \text { inf. } & \text { infinitivo } & 1 & \text { 1a persona singular } \\ \text { inst. } & \text { instrumental } & 2 & \text { 2a persona singular } \\ \text { int. } & \text { interrogativo } & 3 & \text { 3a persona singular } \\ \text { iter. } & \text { iterativo } & 1 / 2 & \text { 1a y 2a persona singular y plural } \\ \text { loc. } & \text { locativo } & & \end{array}$




\section{Referencias}

CASO, Alfonso

1993 "El calendario de los tarascos", en La arqueología en los Anales del Museo Michoacano, Angelina Macías Goytia (comp.) y Lorena Mirambell Silva (coord.), México: Instituto Nacional de Antropología e Historia, pp. 299-319.

ClairIS, Christos

1991 "Le parasynthème, ce méconnu", Dibildim, 10, Istanbul.

CHAMOREAU, Claudine

1997 "Las ánimas. Leyenda phurhépecha", Tlalocan XII, México, Instituto de Investigaciones Filológicas, Universidad Nacional Autónoma de México: 271290.

2000 Grammaire du purépecha parlé sur les îles du lac de Patzcuaro (Mexique). Munich: Lincom Europa (Studies in Native American Linguistics, 34).

2003a Purépecha de Jaracuaro, Archivo de Lenguas Indígenas de México, México: Colegio de México.

2003b Parlons purepecha. Paris: l'Harmattan.

"Itinéraires narratifs en purepecha", en Samia Naïm (ed.), Temps et espace, Paris, Peeters (en prensa).

Foster, Mary

1969 The Tarascan Language. Berkeley y Los Angeles: University of California Press.

LEÓN, Nicolás

1993 "Calendario de los tarascos", en La arqueología en los Anales del Museo Michoacano, Angelina Macías Goytia (comp.) y Lorena Mirambell Silva (coord.), México: Instituto Nacional de Antropología e Historia, pp. 43-49. MARTÍNEZ, Maximino

1979 Catálogo de nombres vulgares y científicos de plantas mexicanas. México: Fondo de Cultura Económica.

MONZÓN, Cristina

1998 Los morfemas de espacio del p'urbépecha. Morfosintaxis y significado. Tesis de doctorado, México: Universidad Nacional Autónoma de México.

Paso y Troncoso, Francisco del

1993 "Calendario de los tarascos", en La arqueología en los Anales del Museo Michoacano, Angelina Macías Goytia (comp.) y Lorena Mirambell Silva (coord.), México: Instituto Nacional de Antropología e Historia, pp. 191-200.

STATI, SOrin

1990 Le transphrastique. Paris: Presses Universitaires de France. 
VILLAVICENCIO, Frida

2002 Estructura y cambio del sistema de casos en el purépecha. Del siglo XVII al siglo XX. Tesis de doctorado, México: Colegio de México.

Wolf, Paul de

1989 Seis estudios lingüísticos sobre la lengua phorhé. Zamora: El Colegio de Michoacán. 